\title{
Influence of Trust Factors on Shared Laboratory Resources in a Distributed Environment
}

\author{
Jannicke Baalsrud Hauge ${ }^{1,4}$, Valentin Kammerlohr ${ }^{2}$, Barbara Göbl ${ }^{3}$ and Heiko \\ Duin $^{1}$ \\ ${ }^{1}$ BIBA - Bremer Institut für Produktion und Logistik, Germany \\ ${ }^{2}$ Hochschule für Technik Stuttgart, Faculty of Surveying, Informatics and Mathematics, \\ Germany \\ ${ }^{3}$ University of Vienna, Faculty of Computer Science, Austria \\ ${ }^{4} \mathrm{KTH}-$ Royal Institute of Technolgy, Sweden \\ baa@biba.uni-bremen.de
}

\begin{abstract}
Every collaboration stands on a foundation of mutual trust. This is a pre-requisite for any information sharing as well as the basis to successfully carry out collaborative tasks. This article presents the use case of Open Digital Lab 4you, a digitized laboratory environment, and identifies relevant trust factors based on a literature review and action-based research. In this paper stakeholders' needs and requirements are discussed and these are linked to several, critical aspects of trust when sharing resources among public institutions
\end{abstract}

Keywords: Trust, shared resources, collaboration in distributed environments, information uncertainty, incentives, shared laboratory

\section{Introduction}

During the last decades, new concepts on shared resources have been developed and successfully implemented within the manufacturing industry [1]. As a socio-economic ecosystem, resource sharing involves human and physical resources [2], as well as nonphysical resources. The concept and practice of sharing undergoes a transition from its traditional role towards the so called sharing economy; referring to resources as well as collaborative consumption as described in $[2,3,4,5,6,7]$, all having in common that either individuals or organisations put efforts in jointly utilizing existing resource(s). In this way they will gain benefits in terms of higher utilization of resources, cost benefits, but also through access to knowledge they don't have $[1,2]$.

The operation of laboratories for educational purposes is an example that might benefit from implementing the concept of shared knowledge, infrastructure and facilities. It is a costly activity for any educational or training institution. Laboratories often require specific and expensive equipment and infrastructure as well as trained and skilled workforce. The utilization of highly specialized laboratories is often low [8] and the access is limited to specific user groups, mostly those working or studying in the institution owning the laboratory.

However, several important questions remain. Under which circumstances is it possible to realise different concepts of shared resources? How should the agreement at 
inter-, intra and individual level look like and what are the barriers and the drivers? Are they the same for all industries and how much do they vary? Is it possible to implement the same business models in this public environment as within the manufacturing sector? Educational institutions educating engineering students for fulfilling future needs, have a detailed knowledge about such concepts from the industry as well as long experience in working in inter-organisational research collaborations [9]. Therefore, this knowledge can be used as a background for implementing a concept for shared laboratories for providing students, researchers and staff access to a larger variety of technologies and knowledge than within an organisation. From the aforementioned collaboration and experiences it is known that trust is a pre-requisite for any functioning collaboration, we will first look at this aspect for our case study. Back in 1995, Mayer [10] defined trust as a conscious choice to be vulnerable towards another's actions, without any means to control or monitor and thus solely based on the expectation that the other will perform a certain, important action. While the author's research originally focused on trust dynamics within organisations, this definition certainly holds true in inter-organisational relations as well. Trust problems can be attributed to complexities resulting from: structure of the sharing network, uncertainties underlying the logistics processes, and partner behaviour [11].

The two research questions we will address here are therefore:

- RQ1: Which trust factors have an influence on the inter-organisational and individual level related to shared resources

- RQ2: How does the difference in incentives for different stakeholders and roles influence the collaboration among partners and employees?

The paper is structured as follows: Section 2 describes the research methodology and is followed by a literature review related to trust factors and frameworks for trust factors. Based on this literature review the first relevant factors are identified and applied in a case study. The relation between the stakeholders' needs and requirements and the different trust factors is discussed in section 5. Section 6 summarises the finding and gives an outlook on next steps.

\section{Research Methodology}

A mixed method approach was used for the research: a structured literature review and action-based research in combination with brainwriting [12], in this instance a case study. A literature review (LR) in the field of organisational trust in different fields was carried out. It was based upon [13] three step approach: planning a review, conducting a review, and reporting and dissemination. This analysis helped in identifying the key factors influencing the trust relation, the differentiation between static and process-oriented factors and shed some light in which challenges we might face in order to achieve the long-term goal of establishing distributed laboratory environments.

The action-based research according to Sein, Henfridsson et. al. [14] was carried out as a case study, investigating the current relations and future needs and requirements among the participating organisations. As basis a workshop was conducted where the 
method brainwriting [12] was applied, the consortium partners wrote their ideas on paper following an exchange of the written ideas. The approach of the case study was selected as research method, because of its potential to investigate a phenomenon in its context [15].

\section{Literature Review}

Trust is a diffuse term, and there exist many different definitions $[1,11]$. Determinants of trust are elements, behaviour, and criteria or factors, which characterize trust in relationships [16]. Sharing something takes time, it requires to take others' schedules, needs, desires, abilities and safety into account and also to trust (perceived risk) in regard to theft, strangers, and privacy issues [17]. Resource sharing, as we would like to realise, is a challenging activity with many uncertainties. Irrespective of these trust uncertainties, the functioning of collaboration on shared resources in logistics rests on fulfilment of trust-based requirements. Partners involved in the sharing need to know and trust: (1) states (conditions) of shareable assets in regard to capacity, presence and/or (idle time), capability; (2) previous experience in the sharing of same resource; (3) restrictions and compensation; (4) level of behavioural congruence of actors participating in the sharing; (5) regulatory issues and dispute resolution. [2] further clarifies that partners involved in the sharing have to trust that: service will be delivered to a reasonable standard and expectation. Nevertheless, trust is needed to overcome uncertainties in shared information, fairness of incentive schemes, and partner's in-congruent behaviours [11]. In order to be able to develop and implement a concept of shared laboratory resources, we need to consider the aforementioned findings in our project's context. Therefore, we have analysed different frameworks aiming at describing trust elements from different perspectives.

Daudi et. al. [16] presents a generic trust model in resource sharing and cooperation. It consists of three phases as depicted in Figure 1. Especially differing between static and dynamic factors seems a promising approach, as process-based trust is often not or only superficially discussed in other literature.

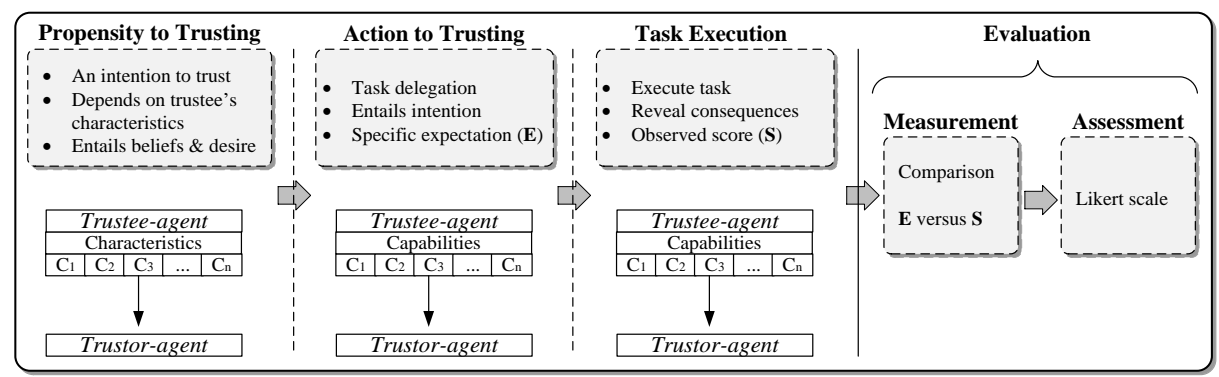

Figure 1. A Generic Model of Trust Mechanisms according to Daudi [16, p. 74]

These generic trust mechanisms are based on a Belief-Desire-Intention model [18], where belief and desire relate to the first phase (propensity to trusting) and intention is 
related to the second phase (action to trusting). Other approaches take a more specific look at trust between organisations and the mechanism as a function of the collaboration phase. As depicted in Table 1, formal institutions, i.e. law and certification, are most important in the early stages of a business relationship and when swift trust is in demand [19]. In both situations there is usually little knowledge available and a weaker form of trust would normally suffice for a (potential) trustor to take the first step. Here it is the antecedent expectations and behaviours that are formed by potential business partners vis-à-vis such conditions that matter. Reputation, as one form of an informal institutional structure, matters most with regard to swift trust development and situations where the products or services exchanged are characterized by a relatively low level of asset specificity. Community norms, structures and procedures are institutional arrangements which matter specifically in mature industries where the players are few, large and well-known [19].

Table 1. Trust Mechanisms and Situations according to Bachmann and Inkpen [19, p. 297]

\begin{tabular}{|c|c|c|c|c|}
\hline & $\begin{array}{c}\text { Legal Regula- } \\
\text { tion }\end{array}$ & Reputation & $\begin{array}{c}\text { Certification of } \\
\text { Exchange Part- } \\
\text { ners }\end{array}$ & $\begin{array}{l}\text { Community } \\
\text { Norms, Struc- } \\
\text { tures and Pro- } \\
\text { cedures }\end{array}$ \\
\hline $\begin{array}{l}\text { Early Stages of } \\
\text { a Relationship }\end{array}$ & $\mathrm{x}$ & (x) & $\mathrm{x}$ & \\
\hline Swift Trust & (x) & $\mathrm{x}$ & $\mathrm{x}$ & \\
\hline $\begin{array}{l}\text { Low Asset } \\
\text { Specificity }\end{array}$ & $(\mathrm{x})$ & $\mathrm{x}$ & $(\mathrm{x})$ & \\
\hline $\begin{array}{l}\text { Mature Indus- } \\
\text { tries }\end{array}$ & (x) & (x) & & $\mathrm{x}$ \\
\hline
\end{tabular}

$\mathrm{x}=$ primary relationship, $(\mathrm{x})=$ secondary relationship

The intended collaboration on shared laboratory resources can be understood as a virtual enterprise defined as: "[...] a special form of a network. Companies are interconnected as a network, for the fulfilment of a concrete task" [20, p. 114]. Regarding trust, [20] identifies different trust relations in virtual enterprises and defines the following main trust decisions that are critical: 1) Trust disposition, 2) Rational calculus, 3) Trust through identification, 4) Positive assessment of abilities, 5) Positive experiences, 6) Transfer of institutional trust and 7) Trust transfer through third parties.

Besides the factors coming into play when considering virtual enterprises, the future cooperation in our remote laboratory environment will be based on roles and less on individuals. It is expected that the sharing of resources will be more a matter of the function and role within an organisation than the personal, individual preference, so that it is matter of role-based trust as defined by [20] and refined by [21, 22] which includes elements of impersonal trust. Nevertheless, Ashnai et. al. [23] emphasize that inter-personal trust is a part of inter-organisational trust as well as a predictor. The authors also discuss the impact of opportunistic behaviour on inter-organisational trust and how inter-organisational trust influences information sharing behaviour. Emotion is identified as main source of inter-personal trust, i.e. when a group or person from a company trusts a group or person in a partner company. Rationality, on the other hand, is the key source for inter-organisational trust, i.e. when a company relies on a partner 
company. Inter-organisational trust, or reliance, is believed to be dependent on factors such as proven capability and expected benefits - hence, objective criteria [25].

Another parallel can be found in service relationships, as discussed by Johnson and Grayson [26]. The authors confirm the importance of the trusting process and summarize four types of trust that play a role of varying importance depending on the stage of the cooperation: 1) Generalized trust; which is based on social norms and refers to a general level of trust in absence of doubt or mistrust. 2) System trust; which is based on rules set by legislative or regulatory authorities as well as on the specific rules and efficiency of enforcement. 3) Process-based trust; which is built on continued interaction in dyadic relationships [27]. This type of trust is based on current and previous behaviour of involved parties and is likely low at the beginning but increases over time. Finally, 4) Personality-based trust depends on the individuals involved and their characteristics. The level of trust is strongly influenced by situational cues. In absence of these cues, personality-based factors become more important. Hence, especially in early stages when situational cues might still be missing, personality-based factors are relevant. Additional to the types of trust, Johnson and Grayson later identify three dimensions, a cognitive, an affective and a behavioural one [28]. The impact of these different dimensions will be investigated at a later stage.

RQ 1 is related to trust in collaborations, and among others [16, 24] have elaborated trust as determinant in collaborations in two different areas: public service and logistics. There are several similarities in their work, so that it can be expected that the identified factors may hold even for the shared laboratory resources which we investigate. For simplification reasons we use the model developed by [16]. Furthermore, Daudi described behavioural elements, as depicted in Figure 2. It establishes how behavioural factors influence trust and articulates parameters (criteria) which constitute each factor [16]. Additional to the discussed static and process-based factors, several measures can be taken to actively support trust building. The usage of platforms can foster trust in several ways, like by assessing partners before, and ratings once those partners have started using the platform's services [27, 29].



Figure 2. Behavioural factors and parameters influencing trust in logistic collaboration according to Daudi [16, p. 43] 


\section{Case Study - The DigiLab4U Project}

As described in the introductions, the main purpose of this paper is to understand how different trust factors affect the collaboration climate. In section 3, the factors identified as relevant by reviewing the literature across several sectors were presented. In the next step, it needs to be validated to what extent these also holds for a specific case - an inter-organisational collaboration on shared resources for public organisations. This is the first part of a larger work, and shall lay the foundation for the development of suitable business models.

\subsection{The DigiLab4U Project}

The cross-institutional Open Digital Lab 4you ${ }^{1}$ (brief: DigiLab4U) project intend to offer a digitized laboratory environment that enables cross-site networking of real and virtual laboratory facilities. The project consortium consists of 2 German and 1 Italian Universities as well as a research institute. Three of them offering education and training in logistics and technology implementation and usage. These are supported by stakeholders with special competence in learning analytics and didactic and educational technologies. The goal is to develop an integrated, hybrid learning and research environment consisting of a large variety of learning materials, data and laboratory technologies as a digital educational offering that can be used by any kind of students from bachelor to doctoral students. It is the intention of the project to enable location-independent access to a digitized and networked learning and research environment in such a way that students located in one place can access laboratories in other places.

\subsection{Identification and Analysis of Factors and the Influence on the Stakeholders}

Although resource sharing is beneficial, there are several challenges to overcome before becoming reality. Besides that, the above mentioned goal requires collaboration agreements between the different institutions as well as suitable collaboration models and business models, taking into account the different needs and incentives of all involved stakeholders at organisational level. As described in the previous section, the success of the intended access to shared resources will, therefore, to a large extent depend on the ability to build trust and mutual understanding. As a first step, a workshop was organised with project members. The objectives were the identification of stakeholders and their requirements on distributed networked laboratories. The method used was brainwriting [12]. Each participant wrote the involved stakeholders and their corresponding needs and requirements on cards. These cards were viewed in the group, discussed and grouped at the end. In total 44 stakeholders and 29 needs and requirements have been identified. The main results are summarised in Table 2. How these are related to the trust factors identified in the literature review is described in chapter 5 .

1 https://digilab4u.com/ 
Table 2. Main results of Stakeholder and their Needs and Requirements from the DigiLab4U workshop

\begin{tabular}{ll}
\hline Stakeholders & Needs and Requirements \\
\hline (a) Students & Knowledge acquisition \\
& Individualisation \\
& Situated and authentic learning \\
(b) Professors & Publications and reputation \\
& Knowledge (that has been transferred) \\
& Better assessment \\
& Time savings \\
& Innovative teaching strategies \\
(c) Universities & Higher quality of teaching \\
& Teaching capabilities \\
(d) Providers & Visibility and reputation \\
& Promotion of Products \\
(e) Companies (as users) & Turnover \\
(f) Researchers & Cutting costs on learning \\
& Publications and reputation \\
& Data for research \\
& New knowledge (on sharing principles and trust) \\
\hline
\end{tabular}

The stakeholders are categorised according to their main usage of the DigiLab4U platform: for training (a, e), teaching (b) and research (f). The Bachelor's or Master's student, a private person or an industrial company use the platform for the purpose of learning (a, e). A professor, a lecturer and/ or a teacher will use the platform for purpose of teaching (b). In addition to the learning, an industrial company, researchers or research organisations can also use the platform for research $(e, f)$. The technical operator is usually equated with the provider, but in the context of digitized laboratory environment the provider may be different from the technical operator (d). With respect to DigiLab4U, the providers are the consortium partners, and can be extended by further partners from research and industry. Universities and research institutions, as well as other third parties, may take on the role of sponsor or sales partner, which were eventually added by analysis of the workshop (c).

\section{Discussion}

The above mentioned approach and analysis of stakeholders as well as their needs and requirements contributes to the research on shared laboratory resources in many ways. In combination with the presented literature review, the analysis in the previous section can help to identify factors which are of special relevance. It is a first step for identifying and understanding the interrelation and the goals of the different stakeholder groups. The description of stakeholders and their motives in itself support a better understanding of involved roles. This enables trust relations to be more easily developed [22]. This is important in remote settings or early stages of a cooperation where hardly any trust based on personal relations has embraced or for organisational trust, where other factors have to support initial trust building [26]. As can be seen above, the need 
for reputation is a common need for several stakeholder groups. According to Table 1 $[7,9,11,19]$ reputation is heavily linked to trust. As mentioned in section 3, establishing rating systems can serve the trust-building process. These systems seem especially relevant in light of the identified needs, as these ratings can support both initial trust and serve the stakeholder's need for improving their reputation as well. Another interesting factor in this specific setting is information-sharing, identified as a part of processbased trust $[16,26]$, which may serve both the trust-building process and the need for knowledge acquisition, which is associated with several stakeholders.

The mentioned requirements such as cost savings, promotion of products and turnover, may be linked to the behavioural factors related to incentive scheme as displayed in Figure 2 [16]. From the business model perspective, the main challenge for the growth of the sharing economy is to establish trust [31] as depicted in [2, 26]. Common market methods compared to physical markets is the possibility of establishing a transparent evaluation system for the quality and reliability of transaction partners, especially providers [23]. [32] describes this as Customer Relationship in the Business Model Canvas, which needs to be taken into account. In the environment of the Shared Laboratory, the relationship and trust concerns are mainly related to the key partners. Therefore, it is important to understand which stakeholders influence the business model, which impact they may have [32].

\section{Conclusion and Outlook}

This paper presents an overview of trust and determining factors in a setting of shared lab environments. A combination of action-based research and a literature review is used to discuss the importance of these factors. Based on the discussed findings, it can be concluded that further investigation of the interaction between the different trust factors, the stakeholders and needs in collaboration can be carried out for a deeper understanding of the interactions as well as to understand different incentives affect the organisational and individual engagement in the shared resources. As stated in $[1,9]$ simulations and games used in a workshop setting or as a multi-player game seem to be suitable tools for this purpose. Therefore, the next step will be to develop a serious multi-player game in which the different interactions and relations can be investigated. The game's scenarios, stories and tasks will be based on relevant, collaborative use cases, and the identified trust factors will be integrated into the game's design. Eventually, analysing individual and cooperative game play can help to assess identified trust factors and dependencies. In addition, analysis of the stakeholders through user stories would give a more detailed insight into the respective roles such as administration, marketing, decision makers or data protection officer.

\section{Acknowledgement}

This work has been funded by the German Federal Ministry of Education and Research (BMBF) through the project DigiLab4U (No. 16DHB2112/3). The authors wish to 
acknowledge the BMBF for their support. We also wish to acknowledge our gratitude to all DigiLab4U project partners for their contribution.

Barbara Göbl is supported by a DOC-team fellowship of the Austrian Academy of Sciences.

\section{References}

1. Baalsrud Hauge, J., et. al.: Collaborative Serious Games for Awareness on Shared Resources in Supply Chain Management. In: Grabot B. et. al. (eds) Advances in Production Management Systems. APMS 2014. IFIP Advances in Information and Communication Technology, vol 439. Springer, Berlin, Heidelberg (2014)

2. Goudin, P.: The Cost of Non- Europe in the Sharing Economy. Brussels: European Union (2016). http://doi.org/10.2861/26238

3. Daudi M., et. al.: A Trust Framework for Agents' Interactions in Collaborative Logistics. In: Freitag M., Kotzab H., Pannek J. (eds) Dynamics in Logistics. Lecture Notes in Logistics. Springer, Cham (2017)

4. Frenken, K., Schor, J.: Putting the sharing economy into perspective. Environmental Innovation and Societal Transitions, pp. 3-10 (2017). http://doi.org/10.1016/j.eist.2017.01.003

5. Gesing, B.: Sharing economy logistics: Rethinking logistics with access over ownership. Troisdorf, Germany (2017). http://www.dhl.com/content/dam/downloads/g0/about_us/logistics_insights/DHLTrend_R eport_Sharing_Economy.pdf

6. Schönberger, J., Kopfer, H., Kotzab, H.: A Micro- and Macroeconomic View on Shared Resources in Logistics. In H. Kotzab, J. Pannek, \& K.-D. Thoben (Eds.), Dynamics in Logistics: Proceedings of the 4th International Conference LDIC, 2014 Bremen, Germany. Cham: Springer International Publishing, pp. 3-12 (2016). http://doi.org/10.1007/978-3319-23512-7_1

7. Tussyadiah, I. P.: An Exploratory Study on Drivers and Deterrents of Collaborative Consumption in Travel. In Information and Communication Technologies in Tourism 2015. Cham: Springer International Publishing, pp. 817-830 (2015). http://doi.org/10.1007/9783-319-14343-9_59

8. Heradio, R., et. al.: Virtual and remote labs in education: A bibliometric analysis. In: Computers \& Education , pp. 14-38 (2016). https://doi.org/10.1016/j.compedu.2016.03.010

9. Thoben, K-D et. Al: Training through Gaming: Applying a Simulation Based Business Game to Train People for Collaboration in Virtual Enterprises. In: Online Educa Berlin 2005. International Conference on Technology Supported Learnig and Training (2006)

10. Mayer, R. C.: An Integrative Model of Organisational Trust. Academy of Management Review (1995)

11. Daudi, M., et. al.: Behavioral factors influencing partner trust in logistics collaboration: a review. Logistics Research, 9(1), 19 (2016). http://doi.org/10.1007/s12159-016-0146-7

12. Wilson, C.: Brainstorming and Beyond: A User-Centered Design Method. Burlington: Elsevier Science, pp. 43-60 (2013). https://doi.org/10.1016/C2012-0-03533-8

13. Tranfield, D., Denyer, D., Smart, P.: Towards a Methodology for Developing EvidenceInformed Management Knowledge by Means of Systematic Review. Br J Management 14(3), pp. 207-222 (2003). https://doi.org/10.1111/1467-8551.00375 
14. Sein, M. K., et. al.: Action Design Research. MIS Q 35(1), pp. 37-56 (2011). DOI: $10.2307 / 23043488$

15. Yin, R. K.: Case study research: design and methods, 4. ed. London: SAGE (2009)

16. Daudi, M.: Trust in Sharing Resources in Logistics Collaboration (2018)

17. Buczynski, B.: Sharing is Good: How to Save Money, Time and Resources through Collaborative Consumption. Gabriola Island, BC Canada: New Society Publishers (2013)

18. Georgeff M., et. al.: The Belief-Desire-Intention Model of Agency. In: Müller J.P., Rao A.S., Singh M.P. (eds) Intelligent Agents V: Agents Theories, Architectures, and Languages. ATAL 1998. Lecture Notes in Computer Science, vol 1555. Springer, Berlin, Heidelberg (1999)

19. Bachmann, R.; Inkpen, A. C.: Understanding Institutional-based Trust Building Processes in Inter-organisational Relationships. In: Organisation Studies 32 (2), pp. 281-301 (2011). https://doi.org/10.1177/0170840610397477

20. Fladnitzer, M.; Grabner-Kräuter, S.: Vertrauen als Erfolgsfaktor virtueller Unternehmen. 1. Aufl. s.l.: DUV Deutscher Universitäts-Verlag, pp. 188-197 (2006)

21. Müthel, M.: Erfolgreiche Teamarbeit in deutsch-chinesischen Projekten. Dissertation Universitäit Lüneburg, 2005. Wiesbaden: Deutscher Universitäts-Verlag/GWV Fachverlage $\mathrm{GmbH}$ (2006)

22. Zolin, R., et. al.: Modeling \& Monitoring Trust in Virtual A/E/C Teams. Trust in Virtual Teams. CIFE Working Paper \#62. Stanford: Center for Integrated Facility Engineering (2000)

23. Ashnai, B., et. al.: Inter-personal and inter-organisational trust in business relationships: An attitude-behavior-outcome model. Industrial Marketing Management, pp. 52, 128-139 (2016). https://doi.org/10.1016/j.indmarman.2015.05.020

24. Chen, B.: Assessing Interorganizational Networks for Public Service Delivery: A ProcessPerceived Effectiveness Framework. Public Performance and Management Review 31(3): pp. 172-187 (2008)

25. Jiang, Z., Henneberg, S. C., Naudé, P.: The importance of trust vis-à-vis reliance in business relationships: some international findings. International Marketing Review, 28(4), pp. 318339 (2011). https://doi.org/10.1108/02651331111149921

26. Johnson, D. S., Grayson, K.: Sources and dimensions of trust in service relation-ships. Handbook of Service Relationship, pp. 357-370 (2000)

27. Zucker, L. G.: Production of Trust: Institutional Sources of Economic Structure, 1840-1920. Research in Organisational Behavior, 8, pp. 53-111 (1986)

28. Johnson, D., Grayson, K.: Cognitive and affective trust in service relationships. Journal of Business research, 58(4), pp. 500-507 (2005)

29. Westphal I., et. al.: Measuring Collaboration Performance in Virtual Organizations. In Camarinha-Matos L.M., Afsarmanesh H., Novais P., Analide C. (eds) Establishing the Foundation of Collaborative Networks. PRO-VE 2007. IFIP - The International Federation for Information Processing, vol 243. Springer, Boston, MA (2007). https://doi.org/10.1007/978-0-387-73798-0_4

30. Schallmo, D., et. al. (Hg.): Digitale Transformation von Geschäftsmodellen. Grundlagen, Instrumente und Best Practices. Wiesbaden: Springer Fachmedien Wiesbaden, p. 194 (2017). DOI: 10.1007/978-3-658-12388-8

31. Goudin, P. (Hg.): The Cost of Non-Europe in the Sharing Economy. Economic, Social and Legal Challenges and Opportunities. European Added Value Unit. Brussels: European Parliamentary Research Service, p. 22. (2016)

32. Osterwalder, A., et. al.: Business model generation. A handbook for visionaries, game changers, and challengers. Hoboken NJ: Wiley, p. 204 (2010) 